\title{
Effectiveness of a nurse-led cognitive behavioural therapy intervention in the management of substance abuse amongst selected secondary school students in Ejigbo local government area, Osun state, Nigeria
}

\author{
*Bayo L. AJIBADE ${ }^{1}$, Patience O AMOO ${ }^{2}$, John MAKANJUOLA ${ }^{3}$, Adewale, O. AKINPELU ${ }^{4}$, Zacheus O. \\ OYEWUMI ${ }^{5}$. Raphael A. AYENI ${ }^{6}$ \\ ${ }^{1,2}$ Ladoke Akintola University of Technology, Ogbomoso, Department of Nursing Science Faculty of Clinical Science, \\ College of Health Science, Osogbo. ${ }^{3}$ Ondo State School of Nursing Akure, ${ }^{4,6}$ Federal Medical, Centre, Owo, Ondo State, \\ ${ }^{5}$ LAUTECH Teaching Hospital,Ogbomoso
}

Address for Correspondence: Dr. Bayo Lawal AJIBADE, Osogbo, Osun State, Nigeria. Email: ajibayo2013@gmail.com.

\begin{abstract}
Background: The world today is witnessing an upsurge of issues that are of global dimension, one of which substance abuse is one. Drug abuse which include alcohol, cannabis, cocaine, and heroine has turned many families apart and destroyed lives, corrupted the societal value and prevented many youth from fulfilling their hopes and aspirations. Therefore, the study is to examine the effectiveness of Cognitive Behavioral Therapy intervention in the management of substance abuse among selected secondary students. Methodology: The universe of study consisted of 232 subjects out of which only 129 that were selected randomly completed the programme, it consisted of 70 males and 58 females selected from secondary schools in Ejigbo Local government area through multistage sampling technique. Simple randomization was used in selecting four secondary schools and respondents were selected randomly from the registers of the school selected. The study adopted a quasi- experimental, non- equivalent control group pretest/post-test design with the Cognitive Behavioural Therapy (CBT) Intervention as the therapeutic package and an instrument tagged Cognitive Behavioural Intervention Scale (CBIS) consisting of 53 items was used. Data were analyzed using means test and analysis of covariance (ANOVA). Results: Findings revealed that cognitive behavioural therapy significantly affects substance abuse cessation among the subjects. The therapeutic intervention was of greater efficacy along the gender lines. Conclusion: It was concluded that Psychiatric Nurses should endeavor to accompany the medical regimen with cognitive behavioural therapy in the management of substance abuse to prevent relapse. It was recommended that educational authorities should employ the services of clinical psychologists.
\end{abstract}

Key words: Efficacy, Nurse-led, Cognitive Behavioural Therapy (CBT), Substance Abuse, Ejigbo

\section{Introduction}

The world today is witnessing an upsurge of issues that are of global dimension [1]. These include the dreaded diseases Aids, international Illegal Financial Transaction, Environmental Degradation, World Population, International migration, Refugee problems, outbreak of Ebola and the scourge of drugs and psychotropic substances. These are problems that cut across national boundaries, hence they required global

Manuscript received: $8^{\text {th }}$ Nov 2015

Reviewed: $19^{\text {th }}$ Nov 2015

Author Corrected: $30^{\text {th }}$ Nov 2015

Accepted for Publication: $18^{\text {th }}$ Dec 2015 solution [2]. In Nigeria, previous studies showed that adolescents of both sexes are the group at risk. The abuse of these drugs which include alcohol, cannabis, prescription drugs (stimulants and depressants), cocaine and heroin has turn many families apart, destroyed lives, corrupted the societal values and prevented many youths from fulfilling their hopes and aspirations [3, 4, $5,6]$. The use and abuse of narcotic drugs and psychotropic substances is said to be a fall-out effect of trafficking in drugs in Nigeria. Report has shown that the category of people arrested for drug trafficking are petty traders, the unemployed students and semi-skilled workers [1]. The abuse of various mood-altering 
substances has been reported to be prevalent among the youths Obot [7]. Use of Tobacco and other illegal drug are also a major source of concern. According to Obot [7], in the general population study in Nigeria and among students, the rates of smoking are high and seem to be increasing. The growing consensus among medical expert is that smoking related disorders (especially lung cancer) is on the increase. Alcohol and tobacco share a lot in common. First, they are both licit and legal drugs i.e. the law dares not prohibit their production, sale and consumption. Second, government because of the proclaimed benefits derivable from tobacco and brewing industries in general supports their commercial viability. Third, the value of the two drugs starts early in life and both are known to serve as gateway to the abuse of other psychoactive substances, cigarette smoking and alcohol abuse are responsible for more death and sickness than illicit drug use [7].

In Nigeria, Kolanut, Coffee and Tobacco and their uses started as far back as the history of human race, since earliest time, man searches for herbs and roots, leaves, plant and other substances to relieve pain help to control disease and for maintaining good health wellbeing of the body [8]. Obot [7]. defines tobacco as any substances which when taken into body, alters the body functions resulting in physical, psychological or behavioural changes. Equally, Conner [9] stated that technically, the term tobacco applies to any substances other than food that changes our bodily or mental functions of the living organisms in either positively or negatively [7]. Tobacco or nicotiana contains major species, these are, nicotiana tobacco from which tobacco products are smoking, chewing, snoffing are obtained and nicotiana, Rustria from which nicotinic and citric acid are extracted for the manufacturing of drugs [8]. Tobacco use, mainly in the form of cigarette smoking is one of the major health hazard associated with cancer of the lungs, respiratory and other cardiac problems [7]. Nicotine naturally has narcotic and additive effects. The narcotic components gives the satisfactory feelings which habituated the smokers appear to have after a few pulps of tobacco while the addictive properties enslave smokers to the habit [7]. It has been estimated globally that about a third of the population age 15 years and above are smokers [9]. Obot [7] asserts that cocaine parties, which are usually, made up of a select group of friends and acquaintances are not uncommon today in large urban arrears. According to him, many users are professionals in their 20 's and 30's, others are nouveau riche businessmen or the adolescent children of well to do Nigerians and their friends. The clearest evidence that cocaine and heroine are being abused by a large number of Nigerians can be found in psychiatric hospital records. Several studies using data from these sources and published in scientific journals agreed that the abuse of these two drugs is a major health problem [3, 4, 5, 6, 7. 8, 14]. For instances in the NDLEA [10] report of the 254 patients on admission for drug related problems, 8 of the females and 5 of females abuse cocaine wile 20 of the males abused cocaine in combination with other drugs. In the same survey, 2 females were found to abuse in combination with other drugs. An increasing numbers of Nigerian youth seeking fun or escape from the travails of life by indulging in an alcohol and smoking. Alcoholism is a major social problem in the United States the total economic costs to society from alcohol abuse have been estimated at \#148 billion [11]. According to the National Institute on Alcoholism [12], over 700,000 American receive treatment for alcoholism on any given day. Treatment options have historically consisted of two relatively distinct alternatives: mutual and groups (for example alcoholics anonymous (AA) and professional treatment (for example Mental Health Centre [13]. One of the major effective approaches used to treat alcoholism is cognitive behavioural therapy (CBT) [14, 15, 16]. Despite the effectiveness of CBT with some clients this and other treatment modalities are ineffective with many others wrestling with alcohol dependency [17]. Furthermore, among those who successfully complete treatment, relapse often a problem [17]. Cognitive restriction is a talk therapy that helps one to reframe an earlier negative or irrational belief or understanding what one has heard about things which inhibits the behaviour of set goals or which discouraged one in his/her effort to change his/her behaviour in life [7].

Conceptual Frame-Work:- Cognitive Behaviour Therapy is an active, direct, and short term structural psychological approach based on the therapy that emotion and behaviour experienced by individuals are the consequences of his/her thoughts in that situation [17]. In the perspective of CBT, a situation does not directly affect how a person feels emotionally rather these emotions occur in response to his/her thoughts in that situation. The principle of cognitive-behavioural counseling is to change distorted thoughts to include cognitive and behavioural changes. The core of CBT is to indicate methods on how to change dysfunctional thoughts into sensible, realistic and helpful cognition 
The CBT used in the study was developed on the basis of the rational emotive behavioural therapy and the cognitive theories $[18,19]$. The ABCDE theory of the rational emotive behavioural therapy serves as the core of cognitive-behavioural counseling in this theory: Arepresents activating events, $\mathrm{B}$ - is a belief about their attitude and behaviour to the event, and C- refers to the consequences of improper condition or behaviour. To change dysfunctional B into appropriate attitude and adaptation, dispute (D) is required. When D ends successfully, successful effect (E) can ensue. The conceptual framework of this study is depicted in the Fig 1.

\section{Fig 1- Theoretical Framework for the study}

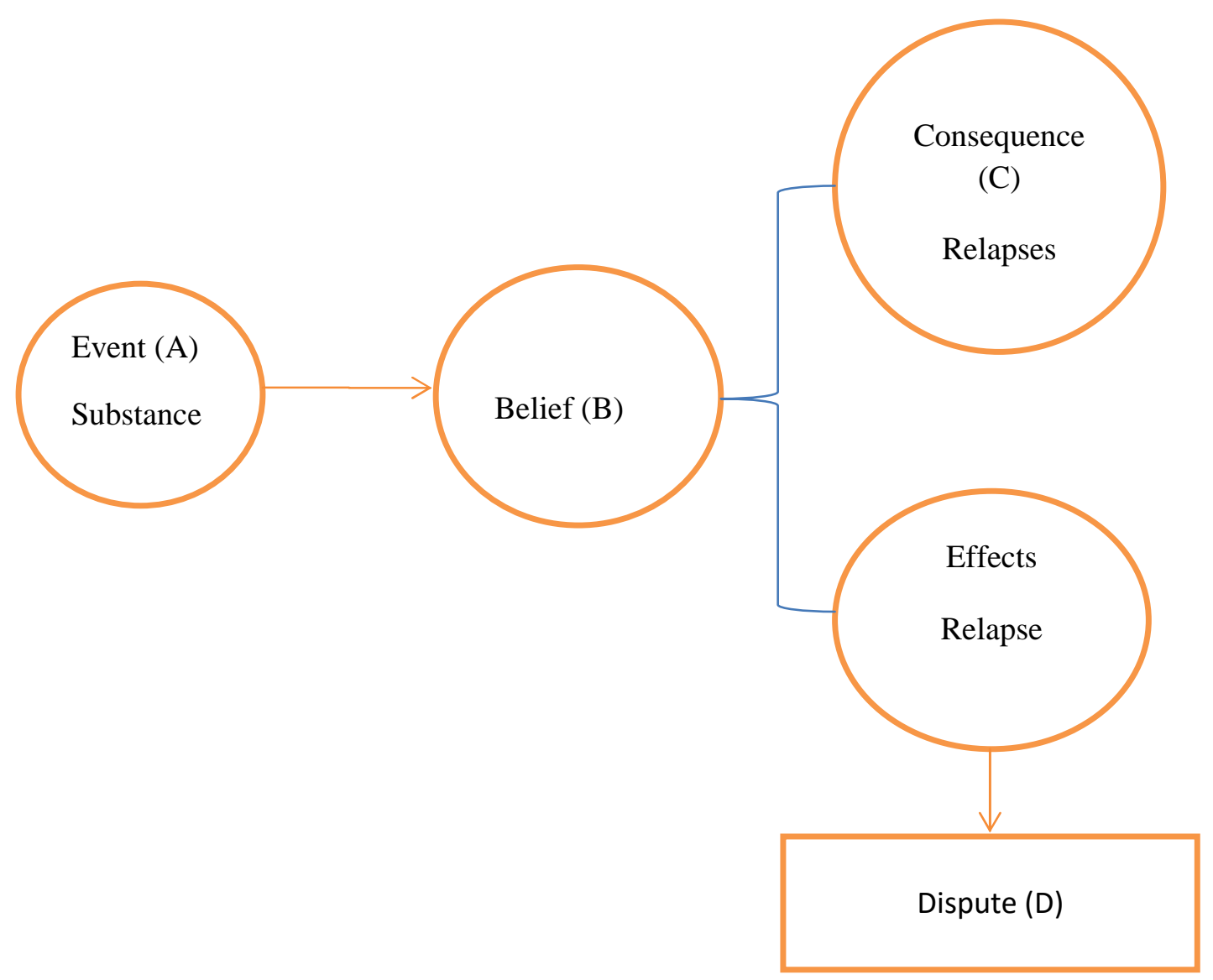

In this study, substance abuse disorder is the activating events (A) for the subjects. The negative emotional responses related to the difficulties with substance use treatment are distorted beliefs (B), which could manifest in malaceptive behaviour. During the process of dispute a nurse- counselor thinking by disputing the dysfunctional beliefs (D). for example, when the subject feels anxious about the relapse of substance use the nurse- counselor disputes the negative thinking. Through this process, the subject realizes that it is more useful to visit clinical psychologist/or mental health nurse to identify the potential relapse of substance abuse, rather than just been anxious. Successful dispute resolution results in the elimination of relapse.

Statement of Problem: The sociological implications of substance abuse among Nigerian youth have a major threat to the peaceful co- existence of all and sundry, thereby destroying the socio- political dignity, personality and integrity of dependence on life. This may be partly attributed to the parental background of the youth, peer influence or over dependence. This is not unconnected to various problems, such as broken homes (divorce), polygamous family, abject poverty, cultural influences parental neglect lack of parental affection and responsibility. For instance, a father that is a drug addict may greatly influence his off-springs. 
In spite of the various efforts by school counselors, psychologist and non-governmental agencies, the national drugs law enforcement agency (NDLEA) and others relevant agencies, the problems of substance abuse (especially tobacco and alcohol) among youths continued unabated.

Therefore this research was to determine the effectiveness of the cognitive behavioural therapy (CBT) in reducing the menace of substance abuse disorder among selected youth in Ejigbo Local Government secondary school.

Objective of the study: - the objective of the study is to:-

1) Determine the efficacy of cognitive behavioural therapy programme on the students mean score on substance abuse cessation of those exposed to therapeutic intervention and those in the central group.

Research Questions:-Two research questions were answered by this research and they were:

1) What is the therapeutic efficacy of cognitive behavioural therapy on the experimental group and the control group?

2) Will the gender of the subjects determine the efficacy of the cognitive behavioural therapeutic programmes?

Hypotheses: Two (2) Null Hypotheses were tested:-

1) There is no significant difference in the efficacy of cognitive behavioural therapy intervention programme on the cessation of substance abuse of those exposed to treatment and those in the central group.

2) There is no significant difference in the interaction efficacy of cognitive behavioural therapy intervention programme and gender on student's substance use cessation post-test mean score as measured by cognitive behavioural scale.

\section{Methodology}

Research Design- The research study employed a quasi- experimental, non- equivalent control group,pretest/post test design.

Research setting- Research was carried out in selected secondary schools in Ejigbo, local government education area of Osun State, Nigeria.

There are 32 secondary schools in the area consisting of both junior and senior secondary school. The local government is one of the 36 local government councils in OsunState in Nigeria. It has eleven (11) wards with Ejigbo township as local government headquarters.

Sample size determination and sampling technique: In determining sample size, Two Yamane (1976) sample size determination method was used.

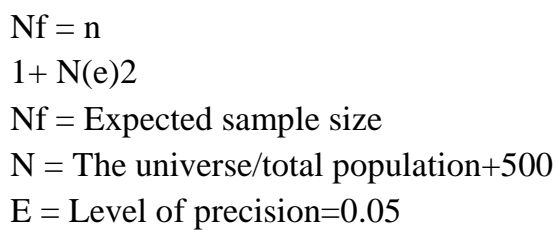

The total population of the four schools selected was 500 .

$\mathrm{Nf}=\frac{\mathrm{N}}{1+\mathrm{N}(\mathrm{e})^{2}}=\quad \begin{array}{r}500(0.05)^{2} \\ \mathrm{Nf}=222\end{array}$

For the purpose of attrition 10 respondents were added resulting in 232 sample size. During the period of introducing the therapeutic package only 129 turned up. Multistage sampling technique was adopted, involving assigning of two of the four schools into experimental and control. 
Instrumentation:- The instrument used for the study was a 13- item Cognitive Behavioural Intervention Scale (CBIS) adopted from Beck $[18,19]$. The items were formulated to extract the values, beliefs and dispositions of subjects on substance abuse cessation. Each item on the questionnaire was rated using likert type of scale on a four point scale of strongly agree (4), agree (3), disagree (2), and strongly disagree (1). The reliability of the instrument was 0.82 using Pearson's product moment correlation.

Analysis of Data:- Data were analyzed using analysis of covariance (ANCOVA).

Treatment Procedure: The treatment procedure covered a period of seven weeks ( 7 weeks). During the first week all the subjects were informed of the procedure and how long it would take.

The CBIS was administered to the both the control and experimental group. The experimental group was using the Baptist High School hall, Ejigbo while the control group was using Baptist High School, Ola (a different of five (5) kilometers apart. Second week involves a play let on substance abuse and the adverse effect.

Third week the introduction of therapeutic package. This runs for $4^{\text {th }}, 5^{\text {th }}$ and $6^{\text {th }}$ week. The subjects were given assignment to take home.

The control group was only counseled and no therapeutic package was administered to them. On the $7^{\text {th }}$ week, both experimental and control groups were administered with the cognitive behavioural intervention scale the scores which served as covariate.

\section{Results}

Table 1: Analysis Showing Treatments by Gender

\begin{tabular}{|l|l|l|l|l|}
\hline Group & Gender & Mean & SD & N \\
\hline \multirow{4}{*}{ Treatment } & Male & 45.35 & 5.07 & 31 \\
\cline { 2 - 5 } & Female & 47.73 & 5.30 & 33 \\
\cline { 2 - 5 } Control & Total & 46.06 & 5.17 & 64 \\
\hline & Male & 32.28 & 9.16 & 40 \\
\cline { 2 - 5 } & Female & 29.56 & 6.73 & 25 \\
\cline { 2 - 5 } & Total & 31.23 & 8.25 & 65 \\
\hline
\end{tabular}

Revealed that male subjects exposed to CBT intervention programme had a post-test mean score of 45.35 with SD of 5.07 as against their male counter parts in the control group with a post-test mean score of 32.28 and an SD of 9.16. the difference in the group was 13.07.female subjected exposed to CBT had a higher post-test mean score of 46.73 with an SD of 5.30 as against the male counterparts the control group of with the post-test mean score of 29.56 with the standard deviation (SD) of 6.73. the difference, in the post-test mean scores of females in the four group is 17.17. the results depicted that male and female subjects in the treatment groups reduce the rate of substance abuse than males and females in the control groups.

Table 2: Test on the effectiveness of cognitive behavioural Therapy (CBT) with reference to cessation of substance abuse between treatment and control.

\begin{tabular}{|l|l|l|l|l|l|l|l|}
\hline Respondent & N & Mean & SD & Df & T cal & T crit & Decision \\
\hline Treatment & 64 & 46.06 & 5.17 & 127 & 12.918 & 1.96 & sig \\
\hline Control & 65 & 31.23 & 7.65 & & & & \\
\hline
\end{tabular}

Showed that't test' analysis value (12.918) was greater than t test table (1.96) at 0.05 levels of significance. The null hypothesis was rejected. This implied that the differences in the mean was significant between the respondents oof treatment and control groups in favours of the treatment groups exposed to training in the use of cognitive behavioural therapy intervention programme on substance abuse cessation. 
Table 3: 2 way analysis of covariance (ancova) on the substance abuse cessarian aong subject as measure by CBIS

\begin{tabular}{|l|l|l|l|l|l|l|}
\hline Source & $\begin{array}{l}\text { Type III Sum } \\
\text { of Square }\end{array}$ & Df & $\begin{array}{l}\text { Mean } \\
\text { Square }\end{array}$ & F & SF & $\begin{array}{l}\text { Decision at } \\
\text { 0.05 Level }\end{array}$ \\
\hline Corrected Model & 10278.706 & 4 & 2569.677 & 40.571 & .000 & S \\
\hline Intercept & 2282.132 & 1 & 2282.132 & 36.033 & .000 & S \\
\hline Pretest & 539.045 & 1 & 539.045 & 8.511 & .004 & S \\
\hline Experimental & 8682.872 & 1 & 8682.872 & 137.099 & .000 & S \\
\hline Gender & 332.946 & 1 & 232.946 & 3.678 & .057 & S \\
\hline Experimental Gender & 11.542 & 1 & 11.842 & .187 & .666 & NS \\
\hline Error & 7853.357 & 124 & 63.334 & & & NS \\
\hline Total & 334660.000 & 129 & & & & NS \\
\hline Corrected Total & 18132.090 & 128 & & & & \\
\hline
\end{tabular}

R. Squared $=.567$ (Adjustem,, ld R Squared $=.553)$

The data presented in table 4 revealed that treatment group as the main factor had a significant efficacy on substance abuse cessation amongst subjects. The f-value of 22.946 was significant at 0.000 levels and also at 0.005 levels of significance. This inferred that the null hypothesis of no significant difference in the efficacy of CBT was rejected. Therefore the alternative hypothesis would be accepted which depicted that there was a significant difference in the substance abuse cessation of the two groups in favour of those exposed to treatment. The adjusted R squared of 0.553 further suggested that $55 \%$ of the total variance on the dependent measures was contributed by treatment using CBT. This evidence depicted the efficacy of CBT in enhancing substance abuse cessation of the subjects in the treatment groups as compared to those in control group.

\section{Discussion}

The results of this study showed that CBT enhanced the cessation of substance abuse any secondary school students. This finding supported the finding of [2] which opined that cognitive restructuring intervention was effective in managing cigarette smoking among adolescent. Equally, this new finding corporated [19] who posited that CBT enhances outcomes in the alcohol consumption [17], supported the finding by saying that CBT medalistic were effective in the management of alcohol dependency. The finding of this study is in line with finding of [14, 15.16] Beck et al [18] Beck [19] who found that students change from the old habit of smoking tobacco to a new behaviour of chewing a tooth pick instead.

Beck et al and Beck [18 and 19] opined that the most prominent health care accrediting organization in the united states attested to the fact that behavioural health organizations is useful in the management of addiction. The finding of this study is consistent with the explanation of the behavioural learning theory that irrational beliefs and mindsets are passively acquired [19].

\section{Conclusion}

It was evidentfrom the study that cognitive behavioural therapy intervention programme significantly effects the substance abuse cessation among secondary school students. Therefore, the use of CBT is efficacious in changing primordial beliefs and negative disposition about substance abuse. Adolescent faulty thinking regarding substance abuse has been replaced any a more accurate behaviour of not abusing substances.

Implication for mental health/ psychiatric nursing practice:

With the outcomes of this finding, it is implicated on the psychiatric nurses to adopt the use of CBT in the management of patients with substance abuse (alcoholism or smoking) aside from medical regimen; thus in essence, will complement the medical regimen. The nurses should be weary of relapses by ensuring that at any follow up visits of patients the practice of CBT should be reinforced.

\section{Recommendation}

- Efforts should be made by the ministry of education to have on part-time basis a clinical/school psychologists. 
- The national drug law enforcement agency (NDLEA) should intensity their anti-drug companies using cognitive behavioural therapy intervention programmes.

Acknowledgement: We acknowledged the permission rendered by the local education authority of Ejigbo local government, the school counselors of the selected 11 . schools and the subjects for the study for their cooperation.

\section{Funding:Nil. Conflict of interest: Nil. Permission for IRB: Yes}

\section{References}

1. Madubike A Ngozi, \& Helen O. Nwagwa (2001). A study of the trend and extent of drug abuse among drug abusers at the NDLEA counseling centre, Lagos.

2. Gambia, Ibrahim A. (1997). The Drugs issue and version 2010 in Nigeria. The International Dimension Paper presented at the National workshop on Drugs and Vision 2010. September 7.

3. National Drug Enforcement Agency (NDLEA, 1991). Drug data collection report. Lagos, Nigeria

4. National Drug Law Enforcement Agency (1992). Drug data collection report. Lagos, Nigeria

5. National Drug Law Enforcement Agency (1997/1999) Lagos, Nigeria Lagos, Nigeria

6. National Drug Law Enforcement Agency (1993). Drug data collection

7. Obot IS. Substance abuse, health and social welfare in Africa: an analysis of the Nigerian experience. Soc Sci Med. 1990;31(6):699-704.

8. Yunusa, U., Abdullahi, M.I., Oliagba, O. sani, S \& Umma, A (2014) The Effect of Cognitive estructuring Intervention on Tobacco smoking among Adolescents in Senior Secondary School in Zaria, Kaduna State, Nigeria, European Scientific Journal; 10 (5), 327-336.
9. Conner, R.J. (1992). Abnormal Psychology, New York, Free man and company

10. Ajibade, B. L. (2015) Substance Abuse among selected Secondary School Students in Osun State, Nigeria, valley international.net/thijsshi 19/11/15.

11. Simon, J, Patel, A. \& Sleed, M. (2005). The costs of alcoholism; Journal of Mental Health, 14, 321 -330.

12. National Institute on Alcohol Abuse and Alcoholism (2000a). New advances in alcoholism treatment. Alcohol Alart, 49 Retrieved from http://pubs.niaaa.nih.gov/publications/aa 49.htm. 10/10/15.

13. Magura S. The relationship between substance user treatment and 12-step fellowships: current knowledge and research questions. Subst Use Misuse. 2007;42(23):343-60.

14. Longabaugh R, Donovan DM, Karno MP, McCrady BS, Morgenstern J, Tonigan JS. Active ingredients: how and why evidence-based alcohol behavioral treatment interventions work. Alcohol Clin Exp Res. 2005 Feb;29(2):235-47.

15. Ellis, A. (2001) overcoming distinctive behaviour, feelings and behaviours; New directions for rational emotive behavior therapy: Amherst, NY: Prometheus Books.

16. Ellis, A. (2005) Cognitive Restructuring Therapy. Iretrieved on 19/10/15 h\#p://www. Njcponline.com cognitive restructuring.

17. Corte, C. (2007), Schema model of the self-concept to examine the role of the self-concept in alcohol dependence and recovery, Journal of the American Psychiatric Nurse Association, 13 (1), 31-41.

18. Beck A.T, Wright F.W., Newman, C.F.\& Liese, B. (1993). Cognitive therapy of substance abuse, New York,NY: Gullford

19. Beck AT. The current state of cognitive therapy: a 40-year retrospective. Arch Gen Psychiatry. 2005 Sep;62(9):953-9. 


\section{How to cite this article?}

Bayo L. AJIBADE, Patience O AMOO, John MAKANJUOLA, Adewale, O. AKINPELU, Zacheus O. OYEWUMI, Raphael A. AYENI . Effectiveness of a nurse-led cognitive behavioural therapy intervention in the management of substance abuse amongst selected secondary school students in Ejigbo local government area, Osun state, Nigeria. Int $J$ Med Res Rev 2015;3(11):1345-1352. doi: 10.17511/ijmrr.2015.i11.244. 